\title{
Shared Decision-Making Preferences in Mental Health: Does Age Matter?
} A Systematic Review

Background: Research to date suggests older adults prefer a passive involvement in the clinical decision-making process; however, the empirical evidence underlying this claim in the mental health context is yet to be reviewed systematically.

Aims: To understand whether older adults desire involvement in mental health-related clinical decisions.

Method: A systematic review was conducted to identify primary research that explored mental-health decision-making preferences of people with a mean age of over 55 from January 1990 through to December 2018.

Results: Three independent studies of varying design and quality were included. Study settings were in the USA, Germany, and the UK. A preference for shared decision-making was seen in two studies, while a preference for active decisionmaking was identified in one.

Conclusions: In contrast to other reviews on clinical decision-making, this review focused on mental health related decisions of older adults. The evidence suggests older adults desire involvement in mental health-related clinical decisions. Given the political drive to empower patients and the need to ensure evidence-based clinical practice, more high-quality research regarding the shared decision-making preferences and outcomes of older adults with mental ill-health is needed.

Declaration of Interest: The authors report no conflict of interest.

Systematic Review Registration PROSPERO: CRD42018102009

Key Words: shared decision-making; mental health; age; older adults; clinical decision-making 
Running Head: Shared Decision-Making, Age and Mental Health

\section{Introduction}

Shared decision-making (SDM) in healthcare emerged as one method to ensure better quality, person-centred healthcare (Makoul \& Clayman, 2006). The term within the healthcare context began in the 1980s but has rose to prominence in the 1990s (Elwyn, Cochran, \& Pignone, 2017). It is a varied concept (Eliacin, Salyers, Kukla, \& Matthias, 2014), that has been widely evaluated (Slade, 2017). In their systematic review Makoul and Clayman (2006) collated elements of 'shared decision-making' (SDM) across the literature into; essential, ideal, and general qualities. From this, the essential qualities of SDM are where both the patient and practitioner exchange information, relay their preferences for action, then discuss and reach an agreement (Charles, Gafni, \& Whelan, 1997; Charles, Gafni, \& Whelan, 1999; Charles, Whelan, Gafni, Willan, \& Farrell, 2003; Shay \& Lafata, 2014; Pollard, Bansback, \& Bryan, 2015; Stiggelbout, Pieterse, \& De Haaes, 2015; Elwyn, Cochran, \& Pignone, 2017; Leng, Clark, Brian, \& Partridge, 2017). The greatest shift towards SDM in the United Kingdom (UK) occurred relatively recently, in the years following 2015, with the establishment of the Shared Decision-Making Collaborative. This collaborative involved a group of organisations and individuals whose aim was to promote and optimise the use of SDM throughout the UK (Joosten, DeFuentes-Merillas, de Weert, Sensky, van de Staak, \& de Jong, 2008).

Research findings relating SDM to age is conflicting. Some studies have identified that younger adults prefer decisions to be shared when compared with older adults (Hill \& Laugharne, 2006; Say, Murtagh, \& Thomson, 2006) while others indicate either no difference between the age groups, or that older adults prefer involvement (Say, Murtagh, \& Thomson, 2006; Eliacin et al., 2014; Xie, Wang, Feldman, \& Zhou, 2014). Many factors may account for these differences. One being, there is no consistency in definition of an 'older person', 
with ages ranging from people over 50 to only those over the age of 75 (Ekdahl, Andersson, Wiréhn, \& Friedrichsen 2011; Jimenez, Bartels, Cardenas, Dhaliwal, \& Alegría, 2012; Michaelis, Kriston, Härter, Watzke, Schulz, \& Melchior, 2017).

The type of health or ill-health examined may impact observed preferences for SDM, i.e. there may be differences in preference when faced with a general health-related decision compared to a mental health-related decision. Two previous reviews focus on patient preferences for decisions relating to physical health (Benbassat, Pilpel, \& Tidhar, 1998; Say, Murtagh, \& Thomson, 2006). These give a useful indication of factors that influence patient's preferences to be involved in SDM, namely: age; gender; education level; and ethnicity. However, neither were systematic in nature, thus may be biased (Podsakoff, MacKenzie, Lee, \& Podsakoff, 2003). Inconsistencies in findings may also stem from the lack of, or unidentified, inclusion of mental ill-health. If these are observed separately from physical disorders, then it may result in a greater understanding of preferences for mental healthcare.

Two systematic reviews (Duncan, Best \& Hagen, 2010; Zisman-Ilani, Barnett, Pavlo, \& O’Connell, 2017) have explored SDM interventions for individuals with mental ill-health. The first review (Duncan et al, 2010) only included two studies, with conflicting results so reliable conclusions could not be drawn. The second (Zisman-Ilani et al., 2017), included 31 records. These studies explored the effectiveness of a SDM intervention on patient engagement, level of involvement and knowledge, as well as outcomes such as adherence and improved health. Another systematic review (Pollard, Bansback, \& Bryan, 2015) explored mental health care and attitudes of the physician towards SDM but did not examine patient views, nor physician characteristics that may influence their attitudes such as their age, sex, or experience.

With nearly half of adults aged over 55 years experiencing some form of common 
Running Head: Shared Decision-Making, Age and Mental Health

mental ill-health such as depression and anxiety (NHS England, 2017), and that adults over the age of 55 account for over half of total health spending (Sawyer, \& Claxton, 2019), coupled with population demographics shifting to older ages (Phelan, \& Larson, 2002) as well as calls from the British Psychiatric Society and researchers alike to increase and improve the mental health services available for older adults (Burns, 2015; Abdul-Hamid, Lewis-Cole, Holloway, \& Silverman, 2015; Royal College of Psychiatrists, 2018), it is increasingly important to understand the mental health needs of this population, and their desire to be involved with SDM given the benefits that implementing this method could bring (Slade, 2017).

Therefore, the current synthesis wishes to build on past research by identifying the preferences of one sub-group in society to allow healthcare professionals to provide more efficient, person-centred healthcare, while gaining evidence to support mental healthcare practice in relation to SDM and identifying gaps to be addressed by future research. 
Running Head: Shared Decision-Making, Age and Mental Health

\section{Methods}

\section{Participants, Intervention, Comparator and Outcome (PICO)}

This paper presents a systematic review based upon the PICO criteria. Participants were adults over the age of 55 years, intervention is shared decision-making, with active and passive decision-making being the comparators and finally, outcome is preference for involvement.

A protocol for this review was registered with the PROSPERO systematic Review protocol registry (registration number: CRD42018102009).

\section{Search Strategy and Selection Criteria}

Electronic searches in Cochrane Library and Prospero were conducted to determine whether the research question had previously been explored. Databases searched were: MedLine, PubMed, PsychInfo and Web of Science between the $1^{\text {st }}$ January 1990 to $1^{\text {st }}$ December 2018. No geographical limits were applied to the search, only articles in English were included due to available time and resources, and only peer-reviewed journal articles were selected. As there are a number of scales available to measure shared decision-making preferences (Scholl, Koelewijn-van Loon, Sepucha, Elwyn, Légaré, Härter, \& Dirmaier, 2011), there will be no restriction on the methods used.

The two older age bands of the Organisation for Economic Co-operation and Development (OECD, 2018) were examined: older adults (55 to 64), and elderly adults (65 years and over).

Articles were included if the aim of the research was to explore, at least in part, the decision-making preference of participants with a mean age of 55 years or older. Studies that compared multiple age groups were included, if the results of the those over 55 could be 
Running Head: Shared Decision-Making, Age and Mental Health

identified separately. Research articles were required to examine the preference towards clinical decisions, including but not limited to psychiatry, medication or treatment, consultation, or general healthcare. The articles must involve participants experiencing, or examining the decision-making of, at least one mental illness, with no restriction regarding the mental illness examined. Any research design could be included given the multidisciplinary nature of this field of research. Finally, only primary research that reported evaluation data was included.

Research was excluded if it did not, at least in part, explore preferences towards SDM. Articles that only explored non-clinical decisions, or decisions regarding physical health were not included. If it was a review article, systematic or otherwise it was also excluded however the reference lists of relevant reviews were searched manually. Clinical reports and clinical aspects, as well as research written in any language other than English or that which proposed or identified models or scales were also excluded.

The full list of search terms, for each database can be seen in the Supplementary Material 1. One reviewer conducted the search (LB); while two independent reviewers checked the methods. Two independent reviewers screened all abstracts, titles, and conducted the eligibility assessment (LB and ADS). Disagreements were resolved by consensus, and a third reviewer screened full texts that could not be resolved in this way (AJ).

The PRISMA checklist was followed in accordance with the guidelines, see Supplementary Material 2 (Moher, Liberati, Tetzlaff, Altman, \& Group, 2009); the PRISMA Search Strategy can be seen in Figure 1.

\section{Risk of Bias, Data Extraction and Analysis}

Risk of bias was assessed through a combination of the Cochrane Risk of Bias for Randomized Control Trial (Higgins, Savović, Page, \& Sterne, 2018) and the Evaluation for 
Running Head: Shared Decision-Making, Age and Mental Health

Qualitative Research (Long \& Godfrey, 2004), to account for a range of study designs. The assessment was done independently by two authors (LB and ADS) and disagreements discussed with a third author (AJ). A copy of the merged form can be found in the Supplementary Material 3. A sample extraction was trialled and tested with an external extractor to test the usability of the merged form. Various aspects of study design, results, conclusions, and potential sources of bias were assessed. Due to the range of research methods used, a narrative data synthesis was adopted.

A Cochrane Extraction template (Higgins \& Green, 2011) was adapted for extraction and piloted to make it applicable and consistent when used with a variety of methodologies. Two reviewers (LB and ADS) independently extracted the data for each study. Inconsistencies in data extraction and quality assessment were clarified by consensus between the two reviewers, with a third reviewer if no agreement could be found. Preference results were defined as active (patient prefers to make the decision about which treatment they will receive), shared (both patient and medical practitioner share responsibility when making treatment decisions), and passive (patients prefer to leave treatment decisions up to the medical practitioner), in accordance with Lechner et al.'s (2016) study.

Given the reported differences in the use of the terminology within the SDM research, elements of SDM included in the different studies were mapped to the Makoul and Clayman (2006) model to ensure comparability of definitions across studies. 
Running Head: Shared Decision-Making, Age and Mental Health

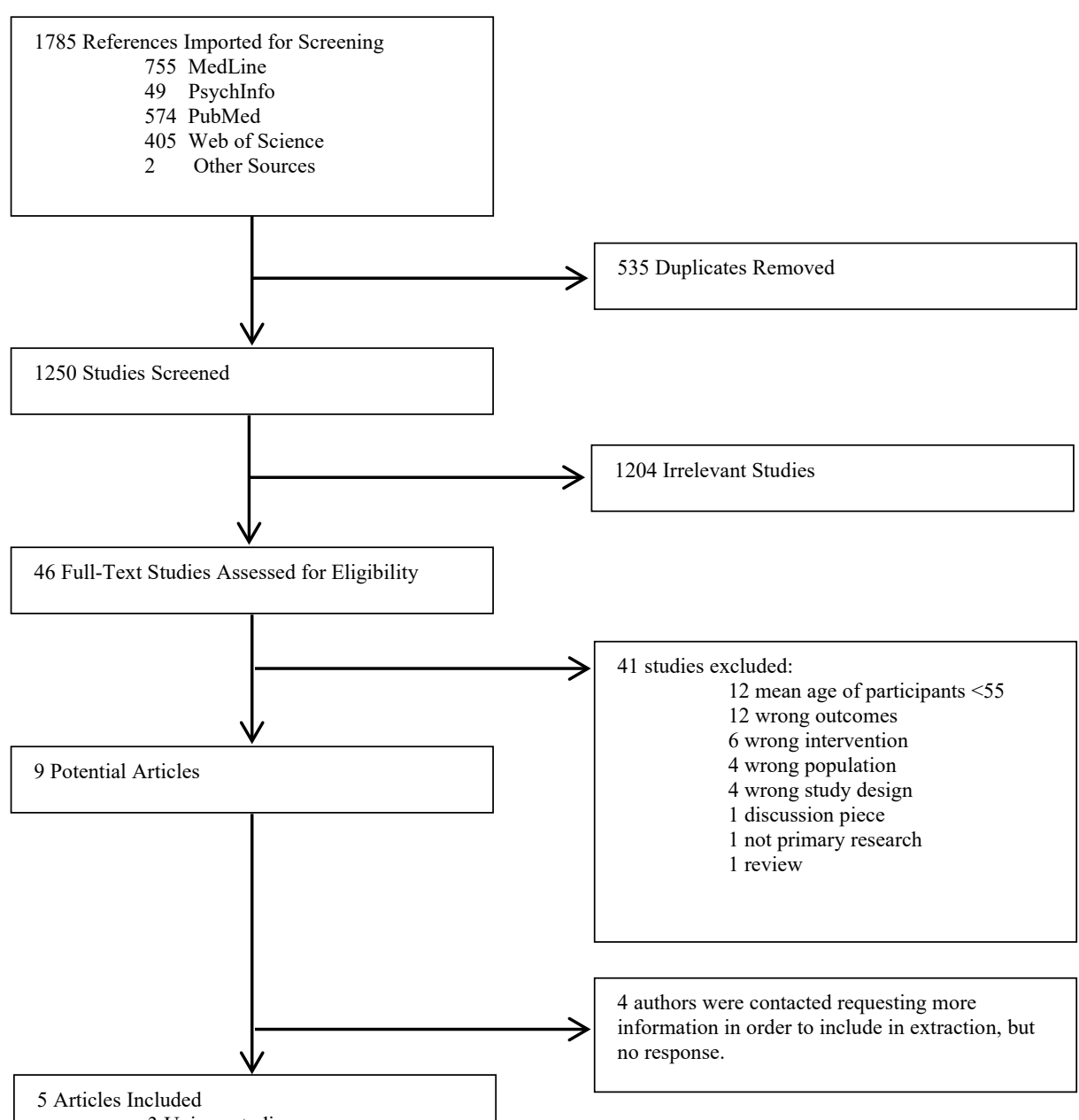

3 Unique studies

Fig. 1: PRISMA Diagram, Search Strategy and Selection Results 
Running Head: Shared Decision-Making, Age and Mental Health

\section{RESULTS}

Figure 1 shows the screening process and search strategy results. Five publications were included, comprising three unique studies. A summary of included articles can be seen in Table 1. Studies took place in USA, Germany and the UK. A total of 3,687 individuals participated (3,124 from Lechner et al., 2016), though some participants may have overlapped (see Table 1; O’Neal et al., 2008; Bartels et al., 2013; Bartels et al., 2014). Three main measures were used: Autonomy Preference Index (API), Control Preferences Scale (CPS), and one video vignette study. The API and CPS are standardised scales for examining clinical preference (Degner, Sloan, \& Venkatesh, 1997; Ende, Kazis, Ash, \& Moskowitz, 1989); the video vignette was created specifically for the study (McKinstry, 2000). Of the three studies, one was deemed to be of high quality, one of moderate quality, and one of low quality, this can be seen in Table 2 along with the decision rationale. Given the small quantity of studies returned, it was decided not to exclude studies based on the Risk of Bias assessment alone, as excluding the studies may result in the inability to answer the research question.

Table 3 displays the classification of the elements of SDM investigated in each of the extracted studies, according to the Makoul and Clayman (2006) SDM model. In all studies SDM included: i) a definition/explanation of the problems; ii) presentation of options; iii) clarifications of patients' values, and iv) a presentation of evidence and recommendations, with remaining five elements varying between studies. A summary of the preference results for each extracted study can be seen in Table 4 .

Overall, two studies identified a preference for SDM, while one identified an active preference. McKinstry (2000) found when combining results of all vignettes, older participants seemed to have a general preference for a direct approach to decision-making, compared those of under the age of 60 . However, participants identified a preference for 
SDM when presented with the Clinical Depression vignette, while a passive preference was seen with the physical health scenarios.

Lechner and colleagues conducted a German population-level study that solely examined the decision-making preferences of people over 55 years of age (Lechner et al., 2016). The evidence shows the subset of individuals who were identified as having clinical depression preferred active involvement (40.3\%), while a smaller proportion preferred passive (35.2\%) and the least preferred shared (24.5\%). Examining the whole cohort of individuals, grouped by age, all age groups preferred active involvement in clinical decisionmaking, followed by shared, then passive.

A combination of three articles by Stephen Bartel's group was labelled as study \#3 in our table, as it was not possible to determine whether these were independent studies (Bartels et al., 2013, 2014; O’Neal et al., 2008). All studies have overlapping inclusion and exclusion criteria and are, at least in part, recruited from community mental health centres in Manchester, New Hampshire, USA (see Table 1). When comparing older to younger adults' decision-making preference, O’Neal's (2008) study described a preference for more active engagement for older adults $(\mathrm{M}=54.46)$ than younger adults $(\mathrm{M}=46.26)$. Both groups overall had an active preference within the information-seeking subscale of the API, though younger adults had a higher score $(M=80.75)$ than older adults $(M=74.81)$. No significant difference in decision-making preferences could be found in Bartels' (2013) research. Preintervention mean scores were 46.9 and post-intervention mean was 46.4 . This score indicates a slight increase towards a preference for less contribution, though still indicative of a shared preference. Bartels' (2014) randomised control trial (RCT) found that older adults prefer shared decision-making. However, this preference became more passive the longer the exposure to the treatment. 
Running Head: Shared Decision-Making, Age and Mental Health

\section{Discussion}

\section{Findings Summary}

Reviews exploring preferences for older adults with mental health related clinical decisions are scarce; those that exist are dated and not systematic in nature. Systematic reviews provide the opportunity to synthesise the research and provide an overview of the quality of the research in question. The articles identified in this review report a variety of methodologies; from case-control studies with a high risk of bias through to the high quality RCTs. Three independent articles were included in our systemic review, with a total of 3,687 individual participants. Of these, one identified a preference for active involvement in mental health related clinical decisions, and two reported a shared preference, though the one RCT identified preferences are susceptible to change. This review suggests older adults prefer to be involved in the clinical decision-making process, though the level of involvement varies across the evidence. Given the quality and limited number of the studies; it is difficult to determine the preference for involvement with complete confidence.

Two standardised measures of reporting patient preferences were used; the Control Preferences Scale (CPS; Degner et al., 1997), the Autonomy Preferences Index (API; Ende et al., 1989), in addition to one video-vignette study that was not standardised. The CPS involves patients organising 5 ranked cards in order of scenario preference, while the API is a 23-item self-reported questionnaire with three dimensions (preferences for general participation, preferences for participation regarding certain diseases, and informationseeking), ratings from 0 ('strongly disagree') to 4 ('strongly agree'). The API has an intraclass correlation coefficient of .7 for test-retest reliability, and a confirmatory factor analysis of .85 for the German version of the scale compared with the original (Simon, Kriston, Loh, Spies, Scheibler, Wills, \& Härter, 2010; Sung, Raker, Myers, \& Clark, 2010; Scholl et al., 2011). The CPS has a test-retest reliability, with an agreement of $90 \%$, and an 
Running Head: Shared Decision-Making, Age and Mental Health

intraclass correlation coefficient of .5 and correlates positively with API (Giordano, Mattarozzi, Pucci, Leone, Casni, Collimedaglia, \& Solari, 2008; Sung, Raker, Myers, \& Clark, 2010; Scholl et al., 2011).

One study identified older adults' preferred collaboration when making mental health related decisions (Bartels et al., 2013, 2014; O’Neal et al., 2008). Though Bartels’ RCT displayed a preference towards SDM, it also shows that preference is fluid and changeable depending on the intervention received (Bartels et al., 2014). Only one study identified older adults had an overall preference for passive involvement in decision-making (McKinstry, 2000), but when isolating the mental health scenario, preference was for SDM, showing preferences change depending on the nature of the illness.

The population-level German study concluded that older people with clinical depression prefer active participation in their own treatment. Notably, though older adults overall preferred involvement in decision-making, the older the participant, the more passive they became (Lechner et al., 2016). Interestingly, this study investigated the greatest number of Makoul and Clayman's (2006) elements of SDM (seven out of nine), which may identify a link between preference outcomes identified in research and number of SDM elements included.

\section{Comparison with Other Literature}

The findings of this systematic review contrast with two earlier reviews, which suggest decision-making preference is influenced by age, specifically; older patients prefer a passive role in decision-making (Benbassat et al., 1998; Say et al., 2006). These reviews were not systematic and did not observe mental health conditions. Other research suggests age has no 
effect on decision-making (Park et al., 2014; Wright-Berryman \& Kim, 2016), while some report older adults prefer SDM over authoritative (Shay \& Lafata, 2015).

Past research was inconsistent when defining an 'older person', ranging from over 50 years old to over 75 years old (Ekdahl et al., 2011; Jimenez et al., 2012; O’Neal et al., 2008; Xie et al., 2014). By using the OECD's two oldest age bands, this systematic review was able to be inclusive when exploring the research surrounding older adults and their SDM preferences.

When comparing older to younger adults' decision-making preference, O'Neal's (2008) study described a preference for more active engagement for older adults $(\mathrm{M}=54.46)$ than younger adults $(M=46.26)$. Both groups overall had an active preference within the information-seeking subscale of the API, though younger adults had a higher score $(\mathrm{M}=$ 80.75) than older adults $(\mathrm{M}=74.81)$. This highlights the difference between informationseeking and decision-making preferences as, in line with past research, there may be variation between desire for information and desire for inclusion in decision-making (Ende et al., 1989; Hill \& Laugharne, 2006). Following Makoul and Clayman's (2006) SDM Model makes it possible to examine the extent that the literature examines SDM and not another form of patient-practitioner interaction, like information-seeking.

Of the studies extracted, one explored $80 \%$ of the SDM elements (Makoul \& Clayman, 2006), two examined $60 \%$, and two $40 \%$ of the elements. The range in scores seen here reflects the ranges seen in Makoul \& Clayman's (2006) citations.

The pattern observed by Lechner et al. (2016), whereby an increase in age sees an increase in SDM preferences, may be linked to cognitive decline. Alternatively, it may be a result of societal or generational beliefs and societal changes (Bynum, et al., 2014). This study only identified clinical depression; though some articles identified schizophrenia disorder as a factor for preferences towards the provider's knowledge over their own to make 
Running Head: Shared Decision-Making, Age and Mental Health

decisions (Park et al., 2014). However, it could also be an effect of the use of a more comprehensive definition of SDM, as this was the only study whereby seven of the nine elements of SDM were included (Makoul \& Clayman, 2006).

Further, there are certain barriers to SDM that are specific to older adults and mental health which may influence an individuals' desire for involvement. For SDM overall, there are patient barriers such as perceived power imbalances, their perceived confidence in own knowledge, or concerns about consequences if patients disagree (Joseph-Williams, Elwyn, \& Edwards, 2014). Older adults may have their own barriers to SDM, such as communication such as hearing loss, speech impediments and slower cognitive processing (Bynum et al., 2014). Finally, specific barriers that can hinder desire to participate in mental health-related decisions include self-stigma and shame (Hamann, Bühner, \& Rüsch, 2017; Slade, 2017, Zisman-Ilani, et al., 2017).

One explanation for the variance between research surrounding decision-making preferences may be that disorder type or severity could influence preference (De las Cuevas \& Peñate, 2014; Park et al., 2014). This could be due to degree of individual or public knowledge surrounding the health problem. McKinstry (2000) states in their discussion, the physical illnesses presented were complex medical problems; therefore, people may have less knowledge of the treatment or clinical options available for these complex problems.

Eligible studies primarily included Caucasian, Westernised individuals with small cohorts, compromising the generalisability of these results. From the findings of the highquality population study and medium quality research studies, it can be argued that Westernised older adults do desire an element involvement in clinical decision-making but cannot be generalised further. 
Running Head: Shared Decision-Making, Age and Mental Health

\section{Research Limitations}

Publication bias will impact any literature review (Rothstein, Sutton, \& Borenstein, 2005), though steps were taken to minimize the influence of bias by searching a number of databases, reviewing reference lists, and extensive search terms. Given the range of research methods, participants and outcomes returned, there was a high level of methodological diversity between studies, preventing any meaningful meta-analysis. Thus, a narrative synthesis was employed.

Only one eligible study conducted a population-level research study, therefore the generalizability of this review is limited, specifically towards Caucasian populations in high income countries. This could either indicate a lack of research in lower income countries or be a result of selection bias (through only including articles written in English). Moreover, three studies were conducted in the same region, and held a consistent, named author; Stephen Bartels (Bartels et al., 2013, 2014; O’Neal et al., 2008). The authors were contacted to confirm the location and discuss potential population overlap, but there was no response. These were included as one unique study to prevent risk of a false negative exclusion.

This review included various methodological designs to reflect the field of SDM. As a result, some of the methods returned are lower on the hierarchy of evidence, such as crosssectional studies and surveys (Evans, 2003).

We defined fifty-five years as the minimum age for inclusion in the review as definitions of "older adult" were inconsistent across the literature (Ekdahl et al., 2011; O'Neal et al., 2008) and this age limit incorporates the two older age bands of the OECD (2018; Geerlings, Beekman, Deeg, \& van Tilburg, 2000; Luoma, Martin, \& Pearson, 2002). Articles with participants above the age of 55 but where the results were not categorised by age group were excluded if the mean age of participants was under 55 years (see 
Supplementary Material 4). Authors of these articles were contacted for further information on preferences of those over the age of 55 only but had no response.

The approach used required the combination of two Risk of Bias forms - one for quantitative and the other for qualitative studies. Steps were taken to finalise the Extraction and Risk of Bias forms, including sampling through an external party. Therefore, it was felt the final forms were the most suitable to cover multiple research designs and included all the necessary questions to identify bias and extract data. The decision not to exclude studies based on the Risk of Bias assessment alone ensured the research question could be answered. Given the conclusions of this systematic review are in concordance with the higher quality research extracted, this decision should be of minimal consequence.

One study included two pilot studies (Bartels et al., 2014; O’Neal et al., 2008), with small sample sizes. These were still included as they explored preferences of individuals. Following the Extraction and Risk of Bias phase, it was noted that one study reported only 17 participants in total, the use of non-parametric testing may have been a more suitable analysis than conducting parametric tests (Bartels et al., 2013). As these are pilot studies, they may be repeated in the future with a wider population, including a greater variety of individuals.

In summary, former reviews, albeit non-systematic in nature, concluded that older adults preferred passive involvement in clinical decision-making rather than shared (Benbassat et al., 1998; Say et al., 2006). This review challenges these findings. Our synthesis of the preferences of older adults on mental health-related decisions shows a preference for a shared or active role.

\section{Implications to Practice, Policy and Research}

Policy makers have advocated for shared decision making based on its potential to improve patients' experiences of healthcare and treatment adherence, while subsequently reducing 
Running Head: Shared Decision-Making, Age and Mental Health

medical costs (Shay \& Lafata, 2015; The Health Foundation, 2012). This review indicates that healthcare professionals should seek involvement from older adults in their mental health clinical decisions and consider any age- and diagnostic- related barriers when doing so.

It is unclear how disorder type or severity, or patient's familiarity of the disorder prior to diagnosis, may impact the patient's preference for involvement, therefore future research should seek to fill this gap. Only a small number of high-quality studies were found in this area, as such any future research conducted should ensure it is of high quality to ensure the results found are reliable. Specific research could further explore the link between SDM preferences, treatment adherence and overall health outcomes for this population using RCTs and cohort studies.

This review article looked at age differences between younger and older adults as an individual patient factor. However, it may be worth exploring the idea that any differences identified could be a result of generational or societal differences, potentially through longitudinal studies (Bynum, et al., 2014).

Given the demographic ageing of the UK and other societies, more evidence is urgently needed to fully understand how SDM impacts on older patients with metal health and psychiatric conditions. 
Running Head: Shared Decision-Making, Age and Mental Health

\section{References}

Abdul-Hamid, W. K., Lewis-Cole, K., Holloway, F., \& Silverman, A. M. (2015).

Comparision of how old age psychiatry and general adult psychiatry services meet the needs of elderly people with functional mental illness: Cross-sectional survey. British Journal of Psychiatry, 207(5), 440-443. https://doi.org/10.1192/bjp.bp.114.145706

Bartels, S. J., Aschbrenner, K. A., Rolin, S. A., Hendrick, D. C., Naslund, J. A., \& Faber, M. J. (2013). Activating older adults with serious mental illness for collaborative primary care visits. Psychiatric Rehabilitation Journal, 36(4), 278-288.

https://doi.org/10.1037/prj0000024

Bartels, S. J., Pratt, S. I., Mueser, K. T., Naslund, J. A., Wolfe, R. S., Santos, M., ... Riera, E. G. (2014). Integrated IMR for Psychiatric and General Medical Illness for Adults Aged 50 or Older With Serious Mental Illness. Psychiatric Services, 65(3), 330-337. https://doi.org/10.1176/appi.ps.201300023

Benbassat, J., Pilpel, D., \& Tidhar, M. (1998). Patients' Preferences for Participation in Clinical Decision Making: A Review of Published Surveys. Behavioral Medicine, 24(2), 81-88. https://doi.org/10.1080/08964289809596384

Burns, A. (2015). Better Access to Mental Health Services for Older People. NHS England. Retrieved from https://www.england.nhs.uk/blog/mh-better-access/

Bynum, J.P.W., Barre, L., Reed, C., \& Passow, H. (2014). Participation of Very Old Adults in Healthcare Decisions. Medical Decision Making, 34(2), 216-230. Doi: $10.1177 / 0272989 \times 13508008$

Charles, C., Gafni, A., \& Whelan, T. (1997). Shared Decision-Making In The Medical Encounter: What Does It Mean? (Or It Takes At Least Two To Tango). Social Science \& Medicine, 5, 681-692. Retrieved from https://ac.els-cdn.com/S0277953696002213/1s2.0-S0277953696002213-main.pdf?_tid=447db471-823f-41a9-9046c323ab2948c2\&acdnat=1527243229_0592d315c9a69959ef71ef215e2bcfee

Charles, C., Gafni, A., \& Whelan, T. (1999). Decision-Making in the Physician-Patient Encounter: Revisiting the Shared Treatment Decision-Making Model. Social Science \& Medicine, 49, 651-661. Retrieved from https:/ac.els-cdn.com/S0277953699001458/1s2.0-S0277953699001458-main.pdf?_tid=8efc66ce-43c8-4156-a9ae79c00c1271d1\&acdnat=1527243208_459e673ad62d831498fd397ad5b872f9

Charles, C., Whelan, T., Gafni, A., Willan, A., \& Farrell, S. (2003). Shared Treatment Decision-Making: What Does it Mean to Physicians? Journal of Clinical Oncology, 
Running Head: Shared Decision-Making, Age and Mental Health

21(5), 932-936. Doi: 10.1200/JCO.2003.05.057

De las Cuevas, C., \& Peñate, W. (2014). To what extent psychiatric patients feel involved in decision making about their mental health care? Relationships with socio-demographic, clinical, and psychological variables. Acta Neuropsychiatrica, 26(6), 372-381. https://doi.org/10.1017/neu.2014.21

Degner, L. F., Sloan, J. A., \& Venkatesh, P. (1997). The Control Preferences Scale. The Canadian Journal of Nursing Research, 29(3), 21-43. Retrieved from http://www.ncbi.nlm.nih.gov/pubmed/9505581

Duncan, E., Best, C., \& Hagen, S. (2008, July 16). Shared decision making interventions for people with mental health conditions. (E. Duncan, Ed.), Cochrane Database of Systematic Reviews. Chichester, UK: John Wiley and Sons Ltd. https://doi.org/10.1002/14651858.CD007297

Ekdahl, A. W., Andersson, L., Wiréhn, A.-B., \& Friedrichsen, M. (2011). Are elderly people with co-morbidities involved adequately in medical decision making when hospitalised? A cross-sectional survey. BMC Geriatrics, 11(1), 46. https://doi.org/10.1186/1471-2318$11-46$

Eliacin, J., Salyers, M.P., Kukla, M., \& Matthias, M.S. (2014). Patients' Understanding of Shared Decision-Making in a Mental Health Setting. Qualitative Health Research, 25(5), 668-678. Doi: 10.1177/1049732314551060

Elwyn, G., Cochran, N., \& Pignone, M. (2017). Shared Decision Making-The Importance of Diagnosing Preferences. JAMA Internal Medicine, 177(9), 1239. https://doi.org/10.1001/jamainternmed.2017.1923

Ende, J., Kazis, L., Ash, A., \& Moskowitz, M. A. (1989). Measuring Patients' Desire for Autonomy: Decision Making and Information-seeking Preferences among Medical Patients. Journal of General Internal Medicine, 4, 23-30. Retrieved from https://s3.amazonaws.com/academia.edu.documents/48001136/bf025964852016081220044-

15wco3g.pdf?AWSAccessKeyId=AKIAIWOWYYGZ2Y53UL3A\&Expires $=15450674$ 50\&Signature $=$ LtxyaOQ8EBhXiWQJaAnGTNK2Ksc\%3D\&response-contentdisposition $=$ inline $\% 3 \mathrm{~B}$ filename $\% 3 \mathrm{DMeasuring}$ pat

Evans, D. (2003). Hierarchy of evidence: a framework for ranking evidence evaluating healthcare interventions. Journal of Clinical Nursing , 12, 77-84. Retrieved from https://onlinelibrary.wiley.com/doi/pdf/10.1046/j.1365-2702.2003.00662.x 
Running Head: Shared Decision-Making, Age and Mental Health

Geerlings, S., Beekman, A., Deeg, D., \& van Tilburg, W. (2000). Physical Health and the Onset and Persistence of Depression in Older Adults: An Eight-Wave Prospective Community-based Study. Psychological Medicine, 30, 369-380.

Giordano, A., Mattarozzi, K., Pucci, E., Leone, M., Casni, F., Collimedaglia, L., \& Solari, A. (2008). Participation in Medical Decision-Making: Attitudes of Italians with Multiple Schlerosis. Journal of the Neurological Sciences, 275(1-2), 86-91. Doi:

10.1016/j.jns.2008.07.026

Hamann, J., Bühner, M., \& Rüsch, N. (2017). Self-Stigma and Consumer Participation in Shared Decision Making in Mental Health Services. Psychiatric Services, 68(8), 783788. Doi: 10.1176/appi.ps.201400307

Higgins, J. P., Savović, J., Page, M. J., \& Sterne, J. A. (2018). Chapter 8: Assessing risk of bias in a randomized trial. Retrieved from www.riskofbias.info:

Higgins, J. P. T., \& Green, S. (2011). Cochrane Handbook for Systematic Reviews of Interventions (5.1.0). The Cochrane Collaborations. Retrieved from http://handbook.cochrane.org

Hill, S. A., \& Laugharne, R. (2006). Decision making and information seeking preferences among psychiatric patients. Journal of Mental Health, 15(1), 75-84. https://doi.org/10.1080/09638230500512250

Jimenez, D. E., Bartels, S. J., Cardenas, V., Dhaliwal, S. S., \& Alegría, M. (2012). Cultural Beliefs and Mental Health Treatment Preferences of Ethnically Diverse Older Adult Consumers in Primary Care. The American Journal of Geriatric Psychiatry, 20(6), 533542. https://doi.org/10.1097/JGP.0B013E318227F876

Joosten, E. A. G., DeFuentes-Merillas, L., de Weert, G. H., Sensky, T., van de Staak, C. P. F., \& de Jong, C. A. J. (2008). Systematic Review of the Effects of Shared DecisionMaking on Patient Satisfaction, Treatment Adherence and Health Status. Psychotherapy and Psychosomatics, 77, 219-226. https://doi.org/10.1159/000126073

Joseph-Williams, N., Elwyn, G., \& Edwards, A. (2014). Knowledge is not power for patients: A systematic review and thematic synthesis of patient-reported barriers and facilitators to shared decision making. Patient Education and Counseling, 94(3) 291-309. Doi: 10.1016/j.pec.2013.10.031

Lechner, S., Herzog, W., Boehlen, F., Maatouk, I., Saum, K.-U., Brenner, H., \& Wild, B. (2016). Control preferences in treatment decisions among older adults - Results of a large population-based study. Journal of Psychosomatic Research, 86, 28-33. https://doi.org/10.1016/j.jpsychores.2016.05.004 
Running Head: Shared Decision-Making, Age and Mental Health

Leng, G., Clark, C. I., Brian, K., \& Partridge, G. (2017). National commitment to shared decision making. British Medical Journal, 359, j4746. https://doi.org/10.1136/bmj.j4746

Long, A. F., \& Godfrey, M. (2004). Evaluation Tool for Qualitative Studies Evaluation Tool for Qualitative Studies Evaluation Tool for Qualitative Studies. International Journal of Social Research Methodology Theory and Practice, 7(2), 181-196. Retrieved from http://usir.salford.ac.uk/12970/1/Evaluation_Tool_for_Qualitative_Studies.pdf

Luoma, J.B., Martin, C.E., \& Pearson, J.L. (2002). Contact with Mental Health and Primary Care Providers Before Suicide: A Review of the Evidence. American Journal of Psychiatry, 159(6), 909-916. Doi: 10.1176/appi.ajp.159.6.909.

Makoul, G., \& Clayman, M. L. (2006). An integrative model of shared decision making in medical encounters. Patient Education and Counseling, 60(3), 301-312. https://doi.org/10.1016/J.PEC.2005.06.010

Michaelis, S., Kriston, L., Härter, M., Watzke, B., Schulz, H., \& Melchior, H. (2017). Prediciting the Preferences for Involvement in Medical Decision Making Among Patients with Mental Disorders. PLoS One, 12(8), e0182203. Doi: 10.1371/journal.pone.0182203

McKinstry, B. (2000). Do patients wish to be involved in decision making in the consultation? A cross sectional survey with video vignettes. BMJ, 321(7265), 867-871. https://doi.org/10.1136/bmj.321.7265.867

Moher, D., Liberati, A., Tetzlaff, J., Altman, D. G., \& Group, T. P. (2009). Preferred Reporting Items for Systematic Reviews and Meta-Analyses: The PRISMA Statement. PLoS Medicine, 6(7), e1000097. https://doi.org/10.1371/journal.pmed.1000097

NHS England. (2017). Half of adults aged 55 and over have experienced common mental health problems, say Age UK. Retrieved May 15, 2019, from https://www.england.nhs.uk/2017/10/half-of-adults-aged-55-and-over-haveexperienced-common-mental-health-problems-say-age-uk/

O’Neal, E., Adams, J.R., McHugo, G.J., Van Citters, A.D., Drake, R.E., \& Bartels, S.J. (2008). Preferences of Older and Younger Adults with Serious Mental Illness for Involvement in Decision-Making in Medical and Psychiatric Settings. The American Journal of Geriatric Psychiatry, 16(10), 826-833. Doi:

10.1097/JGP.0b013e318181f992

OECD. (2018). Employment Rate by Age Group (Indicator). https://doi.org/10.1787/084f32c7-en

Park, S. G., Derman, M., Dixon, L. B., Brown, C. H., Klingaman, E. A., Fang, L. J., ... 
Running Head: Shared Decision-Making, Age and Mental Health

Kreyenbuhl, J. (2014). Factors associated with shared decision-making preferences among veterans with serious mental illness. Psychiatric Services (Washington, D.C.), 65(12), 1409-1413. https://doi.org/10.1176/appi.ps.201400131

Phelan, E. A., \& Larson, E. B. (2002). Successful Aging: Where Next? Journal of the American Geriatrics Society, 50(7), 1306-1308. https://doi.org/10.1046/j.15325415.2002.50324.x

Podsakoff, P.M., MacKenzie, S.B., Lee, J-Y, \& Podsakoff, N.P. (2003). Common Method Biases in Behavioural Researcher: A Critical Review of the Literature and Recommended Remedies. Journal of Applied Psychology, 88(5), 879-903. Doi: $10.1037 / 0021-9010.88 .5 .879$

Pollard, S., Bansback, N., \& Bryan, S. (2015). Physician attitudes toward shared decision making: A systematic review. Patient Education and Counseling, 98(9), 1046-1057. https://doi.org/10.1016/J.PEC.2015.05.004

Rothstein, H. R., Sutton, A. J., \& Borenstein, M. (2005). Publication Bias in Meta-analysis. In H R Rothstein, A J Sutton, \& M Borenstein (Eds.), Publication bias in metaanalysis : prevention, assessment and adjustments (pp. 1-7). West Sussex: Wiley. Retrieved from https://www.meta-analysis.com/downloads/Publication-Bias-Preface.pdf Royal College of Psychiatrists. (2018). Suffering in silence: age inequality in older people's mental health care. Retrieved from https://www.rcpsych.ac.uk/docs/defaultsource/improving-care/better-mh-policy/college-reports/college-reportcr221.pdf?sfvrsn=bef8f65d_2

Sawyer, B., \& Claxton, G. (2019). How do health expenditures vary across the population? Retrieved July 2, 2019, from https://www.healthsystemtracker.org/chartcollection/health-expenditures-vary-across-population/\#item-start

Say, R., Murtagh, M., \& Thomson, R. (2006). Patients' preference for involvement in medical decision making: A narrative review. Patient Education and Counseling, 60(2), 102-114. https://doi.org/10.1016/J.PEC.2005.02.003

Scholl, I., Koelewijn-van Loon, M., Sepucha, K., Elwyn, G., Légaré, F., Härter, M., \& Dirmaier, J. (2011). Measurement of Shared Decision-Making - A Review of Instruments. Zeitschrift für Evidenz, Fortbildung und Qualität im Gesundheitswesen, 105(4), 313-324. Doi: 10.1016/j.zefq.2011.04.012.

Shay, L. A., \& Lafata, J. E. (2014). Understanding patient perceptions of shared decision making. Patient Education and Counseling, 96(3), 295-301. https://doi.org/10.1016/J.PEC.2014.07.017 
Running Head: Shared Decision-Making, Age and Mental Health

Shay, L. A., \& Lafata, J. E. (2015). Where Is the Evidence? A Systematic Review of Shared Decision Making and Patient Outcomes. Medical Decision Making, 35(1), 114-131. https://doi.org/10.1177/0272989X14551638

Simon, D., Kriston, L., Loh, A., Spies, C., Scheibler, F., Wills, C., \& Härter, M. (2010). Confirmatory Factor Analysis and Recommendations for Improvement of the Autonomy-Preference-Index (API). Health Expectations, 13(3), 234-243. Doi: 10.1111/j.1369-7625.2009.00584.x

Slade, M. (2017). Implementing Shared Decision Making in Routine Mental Health Care. World Psychiatry, 16(2), 146-153. Doi: 10.1002/wps.20412

Stiggelbout, A. M., Pieterse, A. H., \& De Haes, J. C. J. M. (2015). Shared decision making: Concepts, evidence, and practice. Patient Education and Counseling, 98(10), 11721179. https://doi.org/10.1016/J.PEC.2015.06.022

Sung, V., Raker, C., Myers, D., \& Clarke, M. (2010). Treatment Decision-Making and Information-Seeking in Women with Pelvic Floor Disorders. International Urogynecology Journal, 21(9), 1071-1078. Doi: 10.1007/s00192-010-1155-8.

The Health Foundation. (2012). Summit Report: Leading the way to shared decision making. Retrieved from https://www.health.org.uk/sites/default/files/LeadingTheWayToSharedDecisionMaking. pdf

Wright-Berryman, J. L., \& Kim, H.-W. (2016). Physical Health Decision-Making Autonomy Preferences for Adults with Severe Mental Illness in Integrated Care. Journal of Social Service Research, 42(3), 281-294. https://doi.org/10.1080/01488376.2015.1093580

Xie, B., Wang, M., Feldman, R., \& Zhou, L. (2014). Exploring older and younger adults' preferences for health information and participation in decision making using the Health Information Wants Questionnaire (HIWQ). Health Expectations, 17(6), 795-808. https://doi.org/10.1111/j.1369-7625.2012.00804.x

Zisman-Ilani, Y., Barnett, E., Harik, J., Pavlo, A., \& O’Connell, M. (2017). Expanding the Concept of Shared Decision Making for Mental Health: Systematic Search and Scoping Review of Interventions. The Mental Health Review, 22(3), 191-213. Doi:

DOI:10.1108/MHRJ-01-2017-0002 
Running Head: Shared Decision-Making, Age and Mental Health

Table 1. Overview of Included Studies (Participants and methods)

\begin{tabular}{|c|c|c|c|c|c|c|c|c|c|c|c|c|c|}
\hline \multicolumn{4}{|c|}{ Overview } & \multicolumn{6}{|c|}{ Participants } & \multicolumn{4}{|c|}{ Methods } \\
\hline $\begin{array}{l}\text { Stud } \\
\text { y ID }\end{array}$ & Author & Year & Study Type & Total No. & Participants & $\begin{array}{l}\text { Geographic } \\
\text { Boundary }\end{array}$ & Study Time & $\begin{array}{l}\text { Type of Mental } \\
\text { Ill-Health }\end{array}$ & Co-Morbidity & Recruited From & $\begin{array}{l}\text { Recruitment } \\
\text { process }\end{array}$ & $\begin{array}{l}\text { Instrument/ } \\
\text { Measure }\end{array}$ & $\begin{array}{l}\text { Post- } \\
\text { Intervention } \\
\text { Preference }\end{array}$ \\
\hline$\# 1$ & $\begin{array}{l}\text { Brian } \\
\text { McKinstry }\end{array}$ & 2000 & $\begin{array}{l}\text { Cross- } \\
\text { Sectional } \\
\text { Survey }\end{array}$ & $\begin{array}{l}\text { Total }=410 \\
\leq 60 \text { years }= \\
326 \\
\geq 61 \text { years }= \\
84\end{array}$ & $\begin{array}{l}\text { - Adults } \\
\text { - Adults } \\
\text { accompanying } \\
\text { children } \\
\text { - Attending } \\
\text { appointments }\end{array}$ & $\begin{array}{l}\text { UK, } \\
\text { Scotland }\end{array}$ & $\begin{array}{l}\text { Not } \\
\text { Specified }\end{array}$ & Depression & Unclear & $\begin{array}{l}\text { Participants } \\
\text { approached } \\
\text { while attending } \\
\text { surgery } \\
\text { appointments in } \\
\text { Lothian } \\
\text { practices. }\end{array}$ & $\begin{array}{l}\text { Adults and adults } \\
\text { accompanying } \\
\text { children attending } \\
\text { five general } \\
\text { practices were } \\
\text { invited to take } \\
\text { part. }\end{array}$ & $\begin{array}{l}\text { Interviewer } \\
\text { asked } \\
\text { which } \\
\text { video } \\
\text { vignette the } \\
\text { participant } \\
\text { preferred } \\
\end{array}$ & NA \\
\hline \#2 & $\begin{array}{l}\text { Sabine } \\
\text { Lechner }\end{array}$ & 2016 & $\begin{array}{l}\text { Population - } \\
\text { Based Cohort } \\
\text { Study }\end{array}$ & $\begin{array}{l}\text { Total }= \\
3124 \\
\text { Clinical } \\
\text { Depression } \\
=159\end{array}$ & - Aged 57+ & Germany & $2008-2010$ & $\begin{array}{l}\text { Clinically } \\
\text { Significant } \\
\text { Depression }= \\
5.1 \%\end{array}$ & $\begin{array}{l}\text { Yes }=52.1 \% \\
\text { No }=47.8 \%\end{array}$ & $\begin{array}{l}\text { Recruited from } \\
\text { the ESTHER } \\
\text { cohort. } \\
\text { ESTHER study } \\
\text { recruited its } \\
\text { participants by } \\
\text { their GPs. }\end{array}$ & $\begin{array}{l}\text { Eight-year follow-up } \\
\text { of the ESTHER } \\
\text { Study (July 2000- } \\
\text { December 2002). }\end{array}$ & $\begin{array}{l}{ }^{0} \mathrm{CPS} \\
\text { (German } \\
\text { Version) }\end{array}$ & NA \\
\hline \multirow{3}{*}{$\# 3$} & $\begin{array}{l}{ }^{\Delta} \text { Erica } \\
\text { O’Neal }\end{array}$ & 2008 & $\begin{array}{l}\text { Cross- } \\
\text { Sectional } \\
\text { Observational } \\
\text { Study (Pilot) }\end{array}$ & $\begin{array}{l}\text { Total }=65 \\
\text { Younger }= \\
32 \\
\text { Older }=33\end{array}$ & $\begin{array}{l}\text { Aged } 18+ \\
\text { Serious mental } \\
\text { illness }\end{array}$ & $\begin{array}{l}\text { USA, } \\
\text { New } \\
\text { Hampshire }\end{array}$ & $\begin{array}{l}\text { July - } \\
\text { August } \\
2006\end{array}$ & $\begin{array}{l}\text { Affective } \\
\text { Disorder }= \\
47.7 \% \\
\text { Psychotic } \\
\text { Disorder }= \\
36.9 \% \\
\text { PTSD }=35.6 \%\end{array}$ & $\begin{array}{l}95.6 \% \text { of PTSD } \\
\text { participants also } \\
\text { reported other } \\
\text { forms of mental } \\
\text { ill-health } \\
\text { Unclear on } \\
\text { physical } \\
\text { comorbidities }\end{array}$ & $\begin{array}{l}\text { 3 Community } \\
\text { Mental Health } \\
\text { Centres: } \\
\text { 2x clinic sites } \\
\text { 1x residential } \\
\text { facility for older } \\
\text { people }\end{array}$ & $\begin{array}{l}\text { Convenience } \\
\text { Sampling }\end{array}$ & $\begin{array}{l}{ }^{0} \mathrm{CPS} \\
{ }^{*} \mathrm{API}\end{array}$ & NA \\
\hline & 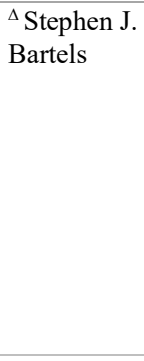 & 2013 & $\begin{array}{l}\text { Pre-Post } \\
\text { Study }\end{array}$ & Total $=17$ & $\begin{array}{l}\text { - Aged 50+ } \\
\text { - Mental Ill- } \\
\text { Health } \\
\text { - } \\
\text { Cardiovascular } \\
\text { risk conditions }\end{array}$ & $\begin{array}{l}\text { USA, } \\
\text { New } \\
\text { Hampshire, } \\
\text { Manchester }\end{array}$ & $\begin{array}{l}\text { Not } \\
\text { specified }\end{array}$ & $\begin{array}{l}\text { Schizoaffective } \\
\text { Disorder }=18 \% \\
\text { Schizophrenia }= \\
41 \% \\
\text { Depression }= \\
18 \% \\
\text { Bipolar }=24 \%\end{array}$ & $\begin{array}{l}\text { Hypertension }= \\
53 \% \\
\text { Diabetes }=47 \% \\
\text { COPD }=12 \% \\
\text { Stroke }=12 \% \\
\text { Asthma }=24 \%\end{array}$ & $\begin{array}{l}\text { 1x state-funded } \\
\text { community } \\
\text { Mental Health } \\
\text { centre } \\
1 \mathrm{x} \text { federally } \\
\text { qualified health } \\
\text { centre } \\
2 \mathrm{x} \text { primary care } \\
\text { practices. }\end{array}$ & $\begin{array}{l}\text { Primary care } \\
\text { providers were } \\
\text { approached. These } \\
\text { providers } \\
\text { identified patients } \\
\text { who fit the } \\
\text { inclusion criteria } \\
\text { ( }>50 \text { yo, a DSM- } \\
\text { IV Diagnosis, and } \\
\text { a cardiovascular } \\
\text { risk factor) }\end{array}$ & *API & Shared \\
\hline & $\begin{array}{l}{ }^{{ }} \text {Stephen J. } \\
\text { Bartels }\end{array}$ & 2014 & $\begin{array}{l}\text { Randomised } \\
\text { Control Trial } \\
\text { (Pilot) }\end{array}$ & $\begin{array}{l}\text { Total }=71 \\
\text { Usual Care } \\
=35\end{array}$ & $\begin{array}{l}\text { - Aged } 50+ \\
\text { - Serious form } \\
\text { of mental ill- }\end{array}$ & $\begin{array}{l}\text { USA, } \\
\text { New } \\
\text { Hampshire }\end{array}$ & $\begin{array}{l}\text { November } \\
2006 \text { - } \\
\text { March }\end{array}$ & $\begin{array}{l}\text { Schizophrenia } \\
\text { Depression } \\
\text { Bipolar }\end{array}$ & $\begin{array}{l}\text { - Hypertension } \\
\text { - Hyperlipidaemia } \\
\text { - Osteoarthritis }\end{array}$ & $\begin{array}{l}\text { 2x Community } \\
\text { Mental Health } \\
\text { Centres (one in }\end{array}$ & $\begin{array}{l}\text { Recruited through } \\
\text { self-referral and } \\
\text { clinical referrals. }\end{array}$ & *API & Shared \\
\hline
\end{tabular}

Page $\mathbf{2 4}$ of $\mathbf{2 8}$ 
Running Head: Shared Decision-Making, Age and Mental Health

\begin{tabular}{|c|c|c|c|c|c|}
\hline $\mathrm{I}-\mathrm{IMR}=36$ & $\begin{array}{l}\text { health } \\
\text { - General } \\
\text { Chronic } \\
\text { Medical } \\
\text { Condition }\end{array}$ & $\begin{array}{l}\text { (Manchester } \\
\text { and Nashua) }\end{array}$ & 2009 & $\begin{array}{l}\text { - Diabetes } \\
\text { - COPD }\end{array}$ & $\begin{array}{l}\text { Nashua, the } \\
\text { other in } \\
\text { Manchester) }\end{array}$ \\
\hline
\end{tabular}

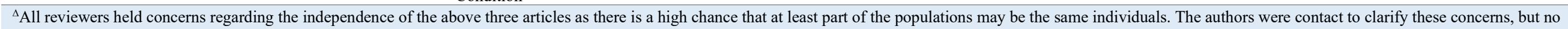
response was received. Therefore, it was decided to take the conservative approach when extracting results from these articles, thus for this review, one 'study' will encompass these three articles.

* API: Autonomy Preference Index (Ende et al., 1989), 23-item self-reported questionnaire, rated from 0 ('strongly disagree') to 4 ('strongly agree')

${ }^{0}$ CSI: Control Preferences Scale (Degner et al., 1997), 1-5 setf-ra

COPD $=$ Chronic Obstructive Pulmonary Disease 
Running Head: Shared Decision-Making, Age and Mental Health

Table 2. Risk of Bias Assessment

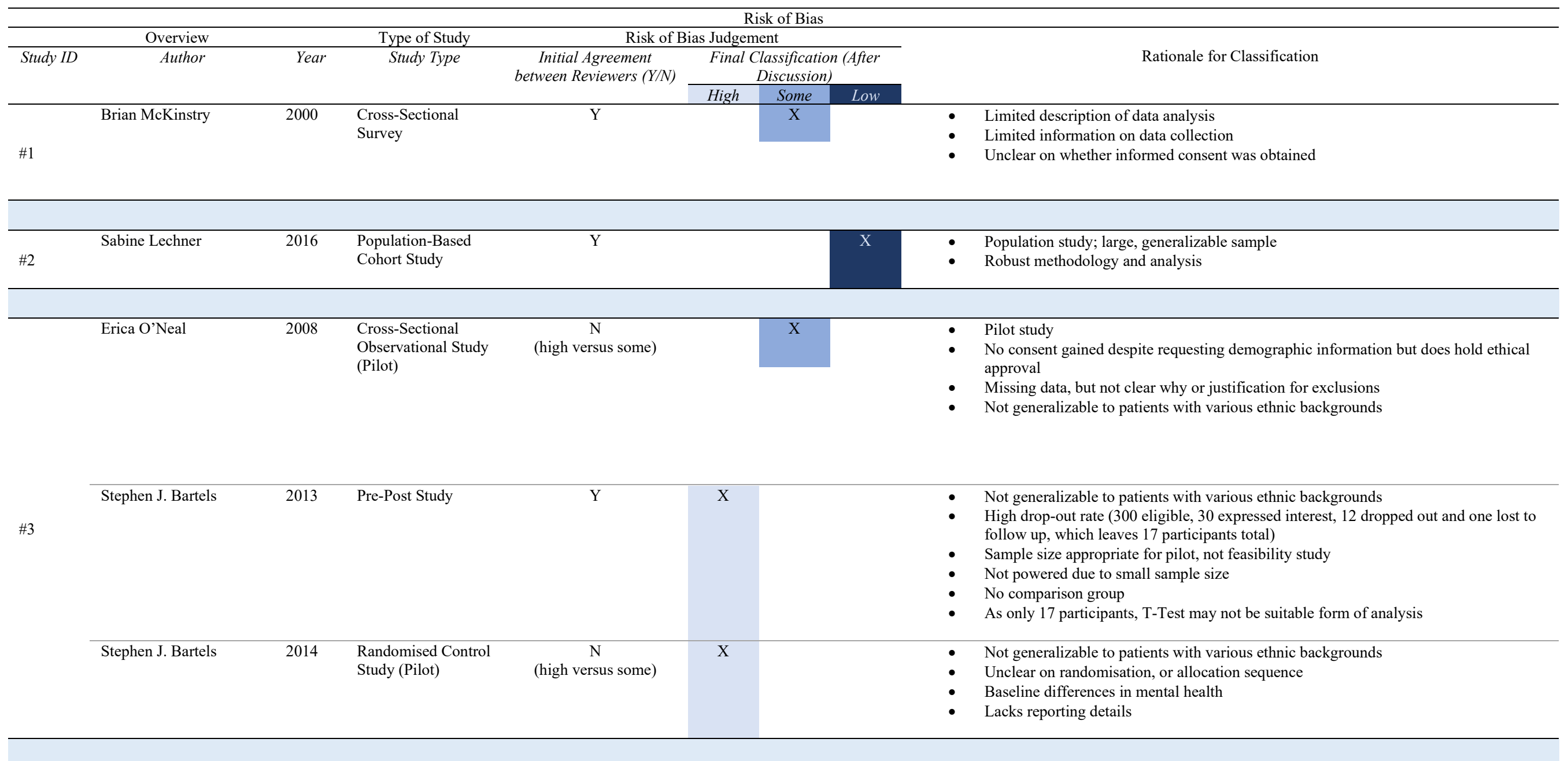


Running Head: Shared Decision-Making, Age and Mental Health

\section{Table 3. SDM Elements and Definitions}

\begin{tabular}{|c|c|c|c|c|c|c|c|c|c|c|c|}
\hline \multicolumn{3}{|c|}{ Overview } & \multicolumn{9}{|c|}{$\begin{array}{c}9 \text { Essential Elements of SDM Investigated in the Studies (Yes/No) } \\
\text { Makoul and Clayman (2006) }\end{array}$} \\
\hline $\begin{array}{l}\text { Study } \\
\text { ID }\end{array}$ & Author & Year & $\begin{array}{l}\text { Define /explain } \\
\text { the healthcare } \\
\text { problem. }\end{array}$ & Present options. & $\begin{array}{l}\text { Discussion } \\
\text { (benefits/ } \\
\text { risks/costs) }\end{array}$ & $\begin{array}{l}\text { Clarify patient } \\
\text { values/ } \\
\text { preferences. }\end{array}$ & $\begin{array}{l}\text { Discuss patient } \\
\text { ability/self- } \\
\text { efficacy. }\end{array}$ & $\begin{array}{l}\text { Present what is } \\
\text { known and make } \\
\text { recommendations. }\end{array}$ & $\begin{array}{l}\text { Check/clarify } \\
\text { the patient's } \\
\text { understanding }\end{array}$ & $\begin{array}{l}\text { Make or explicitly } \\
\text { defer a decision. }\end{array}$ & Arrange follow up \\
\hline$\# 1$ & $\begin{array}{l}\text { Brian } \\
\text { McKinstry } \\
\end{array}$ & 2000 & Yes & Yes & Unclear & Yes & No & Yes & No & Yes & Unclear \\
\hline$\# 2$ & $\begin{array}{l}\text { Sabine } \\
\text { Lechner }\end{array}$ & 2016 & Yes & Yes & Unclear & Yes & Yes & Yes & Yes & Yes & Unclear \\
\hline \multirow{3}{*}{$\# 3$} & $\begin{array}{l}\text { Erica } \\
\text { O’Neal }\end{array}$ & 2008 & Yes & Yes & No & Yes & No & Yes & No & Yes & Unclear \\
\hline & $\begin{array}{l}\text { Stephen J. } \\
\text { Bartels }\end{array}$ & 2013 & Yes & Yes & No & Yes & No & Yes & No & No & Unclear \\
\hline & $\begin{array}{l}\text { Stephen J. } \\
\text { Bartels }\end{array}$ & 2014 & Yes & Yes & No & Yes & No & Yes & No & No & Unclear \\
\hline
\end{tabular}


Running Head: Shared Decision-Making, Age and Mental Health

\section{Table 4: Overview of Results}

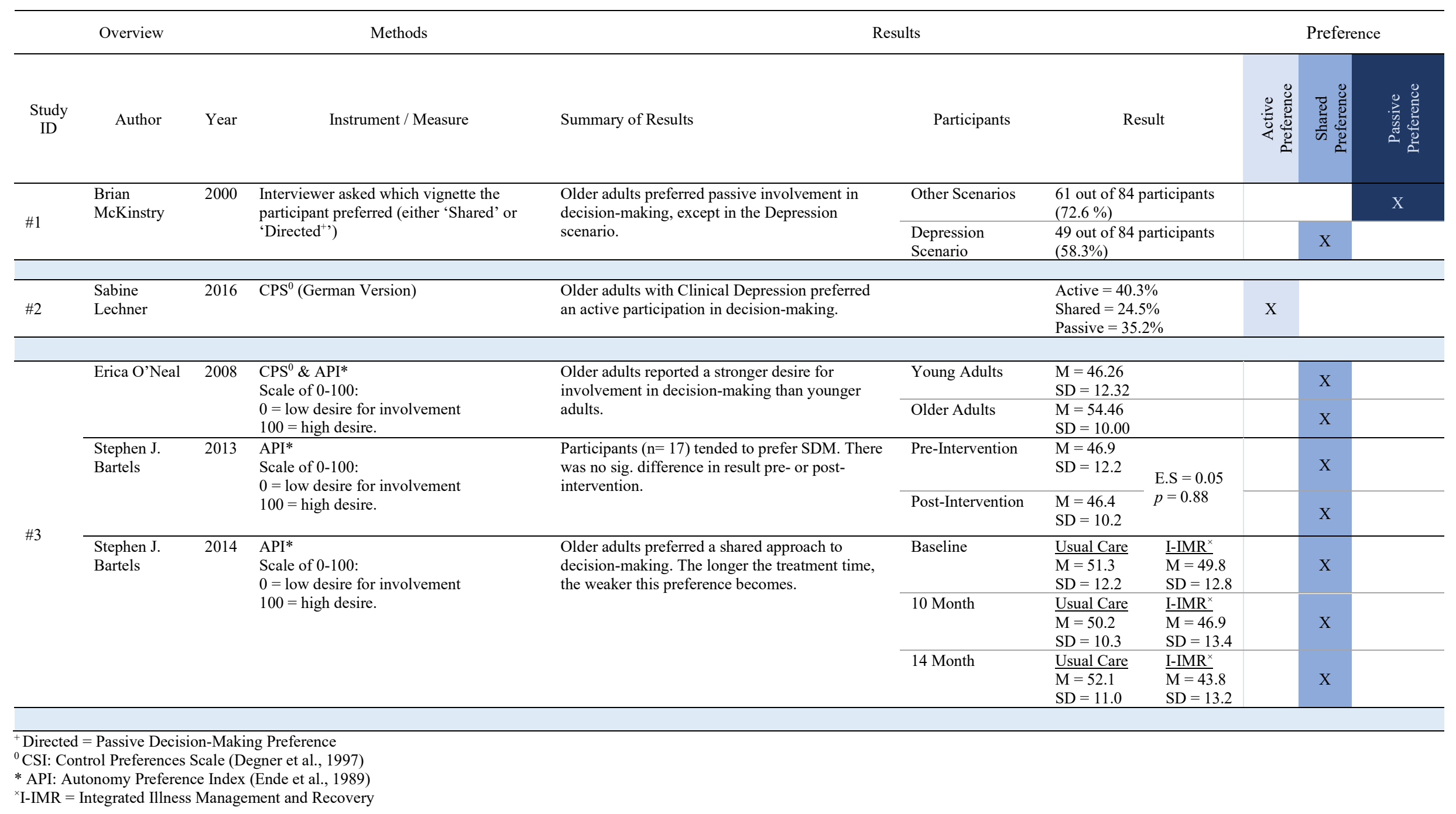

Page $\mathbf{2 8}$ of $\mathbf{2 8}$ 